\title{
Sistemas municipais de ensino no Rio Grande do Sul, Brasil: um olhar atento para o professor
}

\author{
Flávia Obino Corrêa Werle* \\ Carolina Obino Corrêa Werle** \\ Alenis Cleusa de Andrade ${ }^{* * *}$
}

\section{Resumo}

O artigo discute políticas educacionais de âmbito municipal tomando como foco o tema da formação e valorização do magistério. Analisa leis de sistemas municipais de ensino (SME) do Rio Grande do Sul (RS) e a importância da descentralização, da articulação da educação municipal em forma de sistema de ensino. $\mathrm{O}$ trabalho estrutura-se em cinco partes. A primeira apresenta um debate teórico sobre autonomia política de governos locais com base em Giddens (1991, 2002). A segunda analisa as políticas educacionais situando leis de SME como parte do mundo constitucional. A terceira apresenta a valorização do magistério na legislação brasileira. A quarta apresenta a metodologia, enquanto a quinta parte analisa leis de SME de municípios do Rio Grande do Sul explicitando suas características no tocante à importância do professor e do diretor de escola, aos que oferecem apoio pedagógico e aos servidores e funcionários que atuam no SME. Reafirma-se a importância da autonomia política dos governos locais.

Palavras-chave: Educação e Estado. Política e educação. Sistemas de ensino.

\footnotetext{
* Doutora em Educação pela PUCRS; professora do Programa de Pós-Graduação em Educação da Universidade do Vale do Rio dos Sinos.

** Doutora em Ciências de Gestão pela UPMF, Université Pierre Mendes France, Grenoble, Fr. Professora na Grenoble École de Management, CERAG, France.

*** Licenciada em Matemática, mestranda do Programa de Pós-Graduação em Educação da Unisinos.
} 
Este texto discute políticas educacionais de âmbito municipal tomando como foco o tema da formação e valorização do magistério. É um estudo ${ }^{1}$ que, analisando leis de sistemas municipais de ensino (SME), demonstra a importância da descentralização, da articulação da educação municipal em forma de sistema de ensino e destaca a responsabilidade de cada município desenvolver seus próprios caminhos de estruturação da educação local. O argumento principal é o que reafirma a importância da autonomia política dos governos locais ${ }^{2}$, ou seja, a importância de os municípios demonstrarem capacidades de definir e implementar uma agenda política e políticas públicas próprias, mesmo que em nível não tão avançado, apenas mínimo. Ainda que, no Brasil, um dos padrôes de elaboração e de formulação de documentos das políticas decorra de sua origem - geralmente, no núcleo do Estado, nunca da periferia, pois "[...] primeiro sai uma lei ou um decreto federal, a partir da qual leis ou decretos estaduais são promulgados e, em função desses todos, saem leis ou decretos municipais" (CUNHA, 1981, p. 5) -, constata-se que há um promissor e saudável movimento de estruturação das políticas educacionais em nível local, do qual um dos exemplos é a criação de Sistemas Municipais de Ensino. É um movimento que não é extensivo a todos os municípios, que não é homogêneo, que atinge níveis diferentes de maturidade, de desencaixe e de reflexividade. É um movimento inicial em certos municípios e mais aprofundado em outros, nem sempre contínuo e, seguidamente, conflitivo, mas que não pode ser desconhecido ou negado por processos impositivos, centralistas ou desmobilizadores da autonomia local.

$\mathrm{O}$ trabalho estrutura-se em cinco partes. A primeira discute a reflexividade e o desencaixe diante dos processos de autonomia política dos governos locais. A segunda debate as políticas educacionais situando a produção das leis de SME como uma face do mundo constitucional. A terceira aborda a valorização do magistério e a importância desta temática no texto das leis de SME. A quarta apresenta a metodologia de coleta e tratamento dos dados, e a quinta analisa leis de SME de municípios do Rio Grande do Sul explicitando suas características no tocante ao tema.

\section{Reflexividade, desencaixe e autonomia política dos governos locais}

Para discutir as políticas educacionais de âmbito municipal, é importante estabelecer um diálogo com Giddens, especialmente com as 
ideias de reflexividade e desencaixe para melhor situar o argumento da importância e possibilidade da autonomia política local. Entende-se que “[...] o que estrutura o local não é simplesmente o que está presente na cena; a 'forma visível' do local oculta relações distanciadas que determinam sua natureza” (GIDDENS, 1991, p. 27). Giddens (2002, p. 221) está falando de "desencaixe", que consiste no "[...] deslocamento das relações sociais dos contextos locais e sua recombinação através de distâncias indeterminadas do espaço/tempo". A noção de desencaixe acentua a liberação que atores, instituiçóes e fenômenos vão alcançando diante de elos restritos com o tempo e o espaço próximos, quando hábitos e práticas locais passam a ser considerados tradicionais, atrasados, restritivos. Com o deslocamento, as relaçóes sociais são como que removidas de seu contexto, perdendo sua ênfase na situacionalidade e nos vínculos a locais específicos (GIDDENS, 1991, p. 59). É a separação entre tempo e espaço que torna possível a articulação de relaçóes sociais deslocadas do contexto local. Não mais as relaçóes face a face, enraizadas em articulaçôes tecidas pela proximidade física, mas um afastamento do cenário situado, geograficamente, próximo. Entretanto, mesmo num fluxo de desencaixes, ocorrem processos de reflexividade por parte dos atores locais.

O diálogo com Giddens impulsiona a discussão da autonomia da educação local numa perspectiva não superficial ou ingênua, mas no sentido de compreender as contradiçóes e os conflitos que perpassam este nível e que, igualmente, existem nas relaçôes sociais, políticas, econômicas de todos os demais níveis e instâncias. Os desencaixes das relaçôes sociais, que também perpassam as estruturas e relaçôes educacionais, estabelecem, dialeticamente, resultados divergentes e contraditórios entre si. Entretanto, voltando para o argumento da importância da autonomia política dos governos locais - de os municípios poderem demonstrar e desenvolver capacidades de definir e implementar uma agenda política e políticas públicas próprias, mesmo que em nível não tão avançado, apenas mínimo -, o desencaixe e o distanciamento da situacionalidade exigem e favorecem revisóes, rearticulaçóes, retomadas pela reflexividade que potencializa a autonomia política dos governos locais.

A reflexividade institucional é a "[...] reflexividade da modernidade, que envolve a incorporação rotineira de conhecimento ou informação novos em situações de ação que são, assim, reconstruídas ou reorganizadas" 
(GIDDENS, 2002, p. 223). Se as práticas sociais são alteradas pelo desencaixe e pelas reflexividade que passam a reverter sobre elas, informandoas, a autonomia política dos governos locais expressa, na área de educação e das políticas educacionais em conhecimento, repercute, resulta e produz revisôes e, portanto, incrementa esta mesma autonomia política em diferentes níveis. "A reflexividade da vida social moderna consiste no fato de que as práticas sociais são constantemente examinadas e reformadas à luz de informação renovada sobre estas próprias práticas, alterando assim constitutivamente seu caráter" (GIDDENS, 1991, p. 45).

Se a reflexividade inclui a reflexão sobre a natureza da própria reflexão (GIDDENS, 1991, p. 46), a retomada da importância da autonomia política dos governos locais também se inclui neste contexto de discussão. "Nas ciências sociais, temos que acrescentar ao caráter inconstante de todo conhecimento baseado empiricamente a 'subversão' que vem da reentrada do discurso científico social nos contextos que ele analisa” (GIDDENS, 1991, p. 46). Para Giddens (1991, p. 47), há uma “[...] revisão crônica das práticas sociais à luz do conhecimento sobre estas práticas [o que] é parte do próprio tecido das instituiçóes modernas”. Daí a importância de uma relação reflexiva para compreender as práticas indicadoras de autonomia política local, específicas no campo da educação.

$\mathrm{Na}$ discussão acerca da autonomia política dos governos locais, é preciso lembrar que os municípios não são uma voz uníssona, mesmo que assim pareçam ao se articularem de diferentes formas em busca de interesses comuns - associaçóes regionais, união nacional, etc. Entre eles, há intensa diferenciação cultural-sócio-demográfica-econômica-geográfica, bem como educacional. Estudos que problematizam os índices de urbanização do Brasil, por exemplo, subsidiam a reflexão acerca da diferenciação do que, genericamente, chamamos de instância municipal. "Há um oceano de municípios rurais", afirma Veiga (2003), embora dados do ano 2000 indiquem que o País teria atingido $81,2 \%$ de urbanização. ${ }^{3}$ Muitas cidades têm tamanho irrisório, pois toda a sede de município é considerada urbana, mesmo compondo-se de apenas um aglomerado de agricultores e pessoas diretamente envolvidas com atividades primárias. No Brasil, de um total de 5.560 municípios, há apenas 455 que são inequivocamente urbanos, nos quais se concentravam, no ano 2000, 57\% da população nacional (VEIGA, 2003, p. 34). 
Outros autores (BARRETO, 2004; BARRETO; VIGEVANI, 2004) apontam que municípios das capitais e regióes metropolitanas brasileiras assumem, na atualidade, um protagonismo político e econômico inusitado, constituindo-se em atores de relaçóes internacionais. Esta peculiaridade e este dinamismo na cena internacional acrescentam mais um fator de diferenciação entre os municípios brasileiros, além de demonstrar uma forma de desencaixe.

De outro ponto de vista, Duarte (2001) discute o quanto, em matéria de educação, mesmo os municípios de capitais, que poderiam ser atores de maior protagonismo, agem apenas desdobrando políticas educacionais de âmbito federal. A autora, analisando programas educativos das capitais, demonstra, convergindo com a argumentação de Cunha, a restrita autonomia em matéria de políticas educacionais no âmbito municipal, onde há apenas “[...] uma dinâmica de apropriação, de ressignificação de programas e propostas desenvolvidas pelo poder central”. Poucos municípios de capital têm projetos político-pedagógicos próprios, e muitas de suas açôes e propostas estão relacionadas com programas nacionais. A partir de 1996 (Lei de Diretrizes e Bases da Educação Nacional - LDBEN), há uma clara transferência de responsabilidades para o nível local, ficando um vácuo em outros níveis, o qual é preenchido pela União, que instaura programas associados com repasse de recursos e convênios. Ocorre, então, um processo de homogeneização da gestão, pela intervenção e relação direta da União com os municípios e até com as escolas, desconhecendo outras instâncias subnacionais. Ou seja, há uma "[...] forte influência da União na definição de projetos e açóes pelos governos locais." (DUARTE, 2001, p. 13). Nesta mesma linha de argumentos, Vieira (2001, p. 142) identifica, a partir de 1995, a existência de processos de "[...] recentralização das decisóes na esfera federal. Anula-se gradativamente a governabilidade dos Estados sobre decisóes que afetam não apenas os sistemas educacionais, mas o próprio pacto federativo".

A identificação de ingerência e permeabilidade entre as instâncias do Estado (WERLE, 2005a), os procedimentos de assistência técnica e financeira que caracterizam o federalismo de integração ${ }^{4}$ (DUARTE, 2001), a forte influência da União em projetos de educação municipal (DUARTE, 2001), a recentralização de decisóes no poder público federal (VIEIRA; ALBUQUERQUE, 2001) encaminham para que, hoje, de maneira 
marcante, ressurja o eixo interpretativo que identifica o fortalecimento da Uniāo no panorama da federação. Por um lado, há um cenário de grande diferenciação da realidade municipal e, por outro, uma ação da União por sobre todas estas realidades, homogeneizando-as. Esta conflitualidade desdobra-se, produz-se, entretanto, num cenário de reflexividade e desencaixe que pode fortalecer a autonomia do poder local e ajudar a superar problemas de ingerência, de recentralização, de homogeneização.

Este estudo, ao analisar as leis que criam SME, desvela a existência de uma lógica autonomista, não centralista, de assumir responsavelmente as questôes de âmbito municipal.

\section{Políticas educacionais: leis como declaração de intencionalidades de açáo}

Acreditamos, com Stoer e Magalhães (2005), que as políticas são leituras de projetos de mudança social, e que é tênue e complexa a articulação entre implementadores e elaboradores de políticas. Ações de agentes locais podem parecer de cunho eminentemente técnico, entretanto, técnicos e burocratas produzem outras leituras não exatamente convergentes com as dos políticos, ou seja, "[...] a divisão do trabalho não neutraliza as opçóes nem dos políticos nem dos implementadores, nem as remete para um topos político branco, para um 'não-lugar" (STOER; MAGALHÂEES, 2005, p. 23). A operacionalização, ou melhor, a tradução das políticas em açóes e regulamentaçóes pedagógicas e administrativas, portanto, não se dá de forma imediata e determinada.

Da mesma forma, reafirma-se com Dourado (2007) que não se pode reduzir a análise das políticas educacionais e da gestão educacional à mera descrição dos seus processos de concepção e/ou de execução. Os processos de construção de políticas são complexos, pois articulam interesses a propagar e silenciam aqueles que não são relevantes na visão de alguns grupos. Os espaços de prática não são de mera execução, mas de reelaboração, e apropriação política. Ora, a aprovação das leis é apenas uma "fase" do processo pelo qual passam as políticas. Quando em forma de declarações públicas, as políticas educacionais seguem um processo de quatro fases (STROMQUIST, 1996) iniciando-se com a identificação do problema, evoluindo para a formulação e a autorização da política pública (leis 
aprovadas), implementação destas e finalização ou mudança. As políticas públicas náo se apresentam como "[...] um objeto ou texto concreto e constante que se transmite de um local para outro" (STROMQUIST, 1996, p. 27), pelo contrário, são produzidas por indivíduos atuando dentro de contextos, reflexivamente, os quais ora apresentam limitaçóes, ora oportunidades, ora proximidades, ora desencaixes.

Compreendemos, portanto, que os textos legais são uma fase do processo de articulação das políticas educacionais, uma fase à qual não pode ser reduzido todo o processo, diante da qual náo pode ser esquecido o contexto das práticas escolares, com suas forças e limitações. Compreendemos também que os textos legais silenciam certos interesses, enquanto privilegiam outros, embora as forças de tais interesses conflitantes continuem em processos de articulação, buscando expressão, fluindo de diferentes formas por entre instituiçóes e interaçóes sociais. Ou seja, compreendemos que uma afirmativa expressa na lei pode não receber expressão operacional, pode tornar-se inoperante pela inércia dos que teriam a responsabilidade de implementá-la ou pode ser suplantada por forças e interesses contrários que, num determinado momento histórico, conseguem se articular e se formular, assumindo formas operacionais.

Ball (1998) é outro autor que nos auxilia a discutir os processos envolvidos nas políticas educacionais. Para ele, há um contexto de manifestação e de articulação de interesses, no qual alguns temas ganham espaço, enquanto outros não entram na agenda de discussão política. Há também um contexto de formulação das políticas ou de produção de textos legais (designada por Stromquist como fase de autorização da política) em que são explicitadas decisóes e definiçóes políticas, as quais passam a se constituir em declaraçóes de intenção de agir sobre determinados problemas. Há ainda o contexto das práticas, o qual ocorre na escola, mas, também, nas práticas cotidianas de departamentos e de setores situados em diferentes níveis da hierarquia dos sistemas de ensino, e entre estes e os estabelecimentos de ensino.

Mesmo que os textos legais sejam produzidos por negociação, avaliação, reescrita e passem por diferentes comissóes, avaliações técnicas, legislativas, consulta a associaçóes e grupos, quando são recortados, acrescidos, substituídos, seu conteúdo revela uma intenção estruturadora. $\mathrm{Ou}$ seja, as leis e outras formas de expressão das políticas, ao definir instituições, 
estabelecer processos, normatizar e regulamentar ações, se constituem em políticas estruturadoras, estabilizando o funcionamento, os papéis, as finalidades, a forma de organização, ou seja, institucionalizando a educação. Assim, as leis que nascem na instância municipal acatam certos temas, articulam, institucionalizam e estruturam processos mais sintonizados com interesses e forças de âmbito local, embora também sensíveis a processos de desencaixe. Estas leis são elementos do "mundo constitucional”, conforme Frey (2000), apesar de estarem constantemente correndo o risco de seguir cursos não autonomistas - determinados em outros âmbitos, quais sejam, federal ou estadual. Mesmo estruturados no âmbito local, tais documentos do mundo constitucional passam, no contexto das práticas, por "variaçóes, sutilezas e nuances locais (hibridismo)" e por diferentes "graus de aplicação e entusiasmo local (intensidade)" (BALL, 1998, p. 131). A legislação educacional municipal como documento de concepção, de estruturação, de institucionalização e como desdobramento e articulação concreta de processos educativos é um espaço em que as visóes de educação se desenvolvem, manifestando diferenciação, é um espaço de autonomia política dos governos locais. No caso da legislação municipal, aquela "[...] figura abstrata do legislador a idealizar a educação a ser implantada", de que fala Cunha (1981, p. 5), está menos distante da escola, do professor e do cidadão, pois o "núcleo do Estado" está mais próximo e acessível. Ademais, os processos de elaboração das leis de SME são encaminhados, muitas vezes, por meio de processos participativos, o que também ocorre quando da elaboração de planejamentos no âmbito da educação municipal (ASSUMPÇÃO, 2006; GHENO, 2008).

A possibilidade de a instância municipal formular, localmente, propostas, leis e planos educacionais, é evidência, portanto, de um padrão menos verticalista e centralista nas políticas públicas brasileiras. Mesmo com todas as ressalvas anteriormente comentadas, o agir no âmbito municipal, manifestado por documentos de política produzidos localmente para a constituição e estruturação da educação, é um exercício e uma evidência de democratização e extensão de processos mais participativos na sociedade brasileira. Ou seja, manifesta que as regras que vão orientar a ação dos atores - professores, supervisores, alunos, pessoal técnico e administrativo das escolas, colegiados escolares - são produzidas, interpretadas, rearticuladas mais proximamente a tais atores, favorecendo que estes compreendam mais 
amplamente como elas são formuladas e identifiquem possibilidades de nelas intervir e transformar.

Portanto, embora estejamos falando de normas - leis que criam os sistemas municipais de ensino - que se alinham com o eixo da "regulação burocrática” e da autoridade formal, o eixo da diferenciação, da modulação, da influência múltipla e da articulação de relaçóes pelos atores envolvidos localmente ganha força. Ou seja, pelo fato de o "município" ser uma categoria eminentemente diferenciada entre si, considerar os vários atores locais da educação, políticos, burocratas, equipes escolares, colegiados, associaçóes de docentes, clubes de pais, círculos comunitários, implica democratização do poder e disseminação da compreensão de políticas públicas como um espaço em que é possível a ação de outros atores que não apenas o "distante legislador”, em que é possível a autonomia política dos governos locais.

O foco predominante da análise deste texto são os conteúdos concretos das leis de sistema municipal de educação, entendidas estas como uma política estruturadora (FREY, 2000, p. 224) capaz de definir focos, instituiçóes, processos referentes ao campo da educação municipal. Nesta linha de reflexão, é fundamental também a base teórica de Cortesão, Magalhães, Stoer (2001), especificamente na ênfase que atribuem aos tradutores das políticas (comunidade acadêmica, partidos políticos, sindicatos, associaçóes profissionais, etc.) e à importância das opçóes tanto dos políticos que concebem as amplas mudanças políticas e, de alguma forma, as políticas concretas, como dos implementadores das políticas (burocratas, professores, pais), aqueles que estão no espaço das práticas. A análise empreendida neste texto considera predominantemente o contexto (BALL, 2001; LOPES, 2004) da produção de textos legais na instância municipal sob o tema da formação e valorização dos profissionais da educação.

\section{Formação e valorização do profissional da educação nas políticas brasileiras}

$\mathrm{Na}$ história da educação do Brasil, após a Independência, a Lei de 1827 estabelecia a matrícula em escolas de primeiras letras, indicando que seus professores deveriam passar por formação no método do ensino mútuo, custeada por seus próprios salários (TANURI, 2000, p. 62; SAVIANI, 2005, p. 11). De lá para cá, modificaçóes quanto ao tipo, custos, necessidade e 
perfil de formação de professores ocorreram. No que se refere, entretanto, à formação inicial do professor de primeiras letras, a historiografia indica instabilidade e desarticulação, uma trajetória incerta, marcada pela criação, fechamento e nova criação das escolas normais, situação que "[...] ocorreu em todas as províncias durante o período imperial, [...] vindo a se consolidar já no período republicano" (SAVIANI, 2005, p. 12). Entretanto, valorização do professor é mais do que assegurar sua formação inicial. Valorização do professor é considerar as especificidades das condiçóes de trabalho, é identificar a formação como um processo constante, cumulativo e situado, é compreender que a constituição de uma carreira docente contribui para a profissionalização e é um direito do professor.

Mesmo hoje, século XXI, a questão não é isenta de contradiçóes. Há situaçóes em que alguns direitos são retirados aos professores, em que o mecanismo de contratação temporária de docentes marca presença nos sistemas de ensino, em que a remuneração é irrisória, entre outros problemas que evidenciam o nível de valorização do magistério, com repercussão na qualidade da educação escolar.

Nos dias de hoje, é indiscutível a relevância da valorização do magistério. $\mathrm{O}$ mundo constitucional reafirma esta importância desde a Constituição Federal de 1988 (CF/88). A CF/88, no capítulo "Da educação, da cultura e do desporto”, refere o princípio da “[...] valorização dos profissionais da educação escolar, garantindo, na forma da lei, planos de carreira, e ingresso exclusivamente por concurso público de provas e títulos, aos das redes públicas” (BRASIL, 2009, artigo 206, inciso 5, p. 41) e, em seu inciso oitavo, "[...] piso salarial nacional para os profissionais da educação escolar pública, nos termos da lei federal” (BRASIL, 1988, artigo 206, inciso 8, p. 41), indicando para as diversas instâncias do Estado que "A lei disporá sobre as categorias de trabalhadores considerados profissionais $\mathrm{da}$ educação básica e sobre a fixação de prazos para a elaboração ou adequação de seus planos de carreira, no âmbito da União, dos Estados, do Distrito Federal e dos Municípios” (BRASIL, 2009, p. 41).

A Lei de Diretrizes e Bases da Educação Nacional (LDBEN), Lei n. 9.394/96 (BRASIL, 1996), reafirma o princípio da valorização dos profissionais da educação escolar e dedica um título aos profissionais da educação. Nele expressa os fundamentos, os níveis, os tipos de cursos e os programas, detalhando, inclusive, exigências de prática de ensino para a 
formação em nível superior de educadores. Para os temas que nos interessam, quais sejam, a relação entre sistemas municipais de ensino e a valorização dos profissionais da educação, o artigo 67 da LDBEN é fundamental, pois reitera elementos afirmados na CF e identifica outras responsabilidades dos sistemas de ensino.

$\mathrm{Na}$ lei da educação nacional, é claro, portanto, que os sistemas, incluindo os SME, deverão se responsabilizar pela valorização dos educadores e pela normatização por meio de planos de carreira das formas de ingresso, de formação continuada, de remuneração, de progressão na carreira, de tempos para estudo e de condiçóes de trabalho dignas. Assim, um município que cria seu SME necessariamente deverá incluir esta temática na lei que o constitui.

Para além da LDBEN, muitas são as medidas, de âmbito nacional, referentes à formação do professor, nas quais é evidente o protagonismo do governo federal sustentado, em muitos casos, por recursos internacionais. As diretrizes do Plano de Desenvolvimento da Educação (PDE) são um exemplo atual, uma face da tradição centralizadora da instância federal, renovada de forma diferenciada em cada momento histórico. O PDE, lançado pelo governo federal em 24 de abril de 2007, define 28 metas, entre as quais algumas relacionadas diretamente com a situação de trabalho do professor, predominando uma orientação voltada para o mérito e a avaliação do desempenho dos docentes. Entre as metas que se relacionam diretamente com o tema deste artigo, estão:

XIII - implantar plano de carreira, cargos e salários para os profissionais da educaçáo, privilegiando o mérito, a formação e a avaliação do desempenho;

XIV - valorizar o mérito do trabalhador da educação, representado pelo desempenho eficiente no trabalho, dedicação, assiduidade, pontualidade, responsabilidade, realização de projetos e trabalhos especializados, cursos de atualização e desenvolvimento profissional;

XV - dar consequência ao período probatório, tornando o professor efetivo estável após avaliação, de preferência externa ao sistema educacional local; XVI - envolver todos os professores na discussão e elaboração do projeto político pedagógico, respeitadas 
as especificidades de cada escola. (DECRETO 6.094/2007).

Por outro lado, o governo federal desenvolve intensa programação, em todo o País, voltada para a formaçáo inicial e continuada de professores, evidenciando sua forte presença na definição destas políticas, as quais, por serem planejadas, acompanhadas e avaliadas pelo governo federal e executadas com recursos internacionais (VIEIRA, 2008, p. 141), permitem que o perfil dos educadores por elas atingido seja configurado por personagens e em locais distanciados, não identificados com as necessidades locais. Estrela (2007, p. 43) afirma que as políticas educativas nos dias de hoje estão marcadas pela mundialização, que se fortalece e é impulsionada por organismos internacionais como a Unesco e OCDE. Tais organismos pressionam para que as políticas educacionais nacionais priorizem a formação continuada de professores, a qual tem se mercantilizado e desvirtuado em direção à linha de "indústria da formação". Ferreira (2007) também questiona o encaminhamento e o cunho aligeirado que alguns tipos de formação continuada tomam, na medida em que não são convergentes com a progressiva profissionalizaçáo docente e provocam um descomprometimento com a formação inicial e com a valorização dos professores.

Há também que considerar a dissolução das profissões em competências que marca profundamente as modificaçóes ocorridas no mercado de trabalho a partir da década de 1980. O trabalho e a profissão estão sendo dissolvidos diante de demandas como empregabilidade, flexibilidade e adaptação (STOER, MAGALHÁES, 2005, p. 30-36). Este cenário de prevalência das competências diante do trabalho e da profissão repercute também entre os profissionais da educação e exige um pronunciamento dos sistemas de ensino quanto à valorização do professor. É um cenário que se expressa em processos de depreciação do professor e da escola pública; é um cenário que, por vezes, integra nas políticas educacionais as propostas de reconfiguração do profissional em docentes empregáveis, associando índices de desempenho escolar dos alunos e da escola com avaliaçóes externas dos sistemas de ensino e prêmios financeiros para o professor.

A escola pública é o principal espaço de escolarização da população brasileira, entretanto, nela estão ocorrendo processos de pauperização salarial, de precarização das condiçóes de trabalho, com consequentes dificuldades 
em organizar o trabalho coletivo em seu interior. Estas condições são elementos intervenientes e relevantes para o trabalho docente, e não há como estruturar um sistema de ensino municipal sem apontar medidas que promovam a valorização do professor. Portanto, para enfrentar esta situação de desestímulo, a formação docente precisa tornar-se, cada vez mais, um processo de formação intelectual e cultural, que envolve aspectos de natureza ética e política (DIAS-DA-SILVA, 2008, p. 428, 436), e a formação continuada precisa vincular-se com a ação docente nas escolas, exigindo tempo suficiente para que os professores reflitam sobre seu cotidiano e pensem a escola como um projeto comum, um empreendimento compartilhado, pelo qual são co-responsáveis.

Ora, os municípios que se estruturam para articular em sistema a educação não podem silenciar sobre o tema da formação do professor sob o risco de deixarem a escola pública num processo de funcionamento pela inércia e abandono, de se omitirem acerca da importante contribuição destes profissionais para o funcionamento do SME e a qualificação da educação. $\mathrm{Ou}$ ainda, sob o risco de reforçarem e atuarem como meros agentes locais, executores de programas planejados por outras instâncias que desconhecem a realidade municipal e trazem propostas distanciadas de suas necessidades reais. Ademais, se o município está incumbido de oferecer a Educação Infantil em creches e pré-escolas (BRASIL, 1996, artigo11, inciso V), cabe-lhe também a tarefa de definir critérios para a atuação profissional competente nesta fase de escolaridade, bem como estruturar formas de seleção, acompanhamento, avanço e carreira de professores da Educação Infantil e especificar como receberão atualização, como serão apoiados em seu cotidiano de trabalho.

A lei de SME, portanto, como um documento que autoriza, estrutura e institucionaliza açóes públicas, que traça um quadro para o funcionamento da educação local, não pode silenciar acerca da formação e valorização do professor.

\section{Metodologia do estudo das leis de Sistema Municipal de Ensino}

A pesquisa se iniciou com o levantamento de todas as leis municipais que criaram sistemas de ensino, considerando o universo de 496 municípios do Rio Grande do Sul. Para tanto, foi feito contato ${ }^{5}$ com todos os municípios 
do RS. O corpus empírico da investigação constitui-se de documentos de 41\% dos municípios do Estado, ou seja, de 204 documentos que criam SME e dez documentos que alteram leis de SME, que foram tratados integradamente ao documento legal que criou o SME. As leis de criação e as leis de alteração de cada SME foram analisadas em seu conteúdo, tendo sido criadas categorias para apreensão/expressão de seu conteúdo. Tais categorias não foram definidas a priori, mas num esforço de diálogo interpretativo que buscou compreender a multidimensionalidade das políticas educacionais locais, expressa em cada lei de SME. Ou seja, as categorias foram criadas num vai-vem interpretativo e de atribuição de sentido, pela análise do material empírico, pela consideração do quadro legal da educação brasileira e pela mobilização dos fundamentos teóricos do projeto. Foram criadas dez categorias temáticas: estrutura e organização do ensino; instituiçóes escolares, seus níveis e modalidades; gestão democrática; avaliação do sistema de ensino; valorizaçáo do professor; construção de um Plano Municipal de Educação; recursos financeiros para a educação; regime de colaboração com o poder federal e o estadual; ação redistributiva em relação a suas escolas e atenção às peculiaridades locais. Cada lei foi analisada diante de tais categorias, sendo atribuído um valor, considerando o grau de presença, o detalhamento e o nível de operacionalização com que cada categoria se apresentava. Isto é, o valor atribuído a cada categoria decorreu da identificação das formulaçóes temáticas apresentadas em cada lei de SME, bem como do esforço de identificação de sua clareza, especificidade e amplitude. Definiu-se que o valor de cada categoria seria identificado em três níveis: ausente, presente ou presente, e expresso com clareza, de forma a apresentar um nível de significação ampliada da categoria considerada. $\mathrm{O}$ valor atribuído foi pontuado numericamente, com dois, se a presença da categoria era clara, detalhada; com um, se a categoria estava presente na lei, mas náo de forma discriminada, e com zero, se o tema não era citado, se era inexistente na lei. Assim, as leis que mais pontuaram, considerando as dez categorias, obtiveram vinte como pontuação total.

Os valores encontrados para cada lei e cada categoria foram relacionados à data de cada lei no sentido de verificar se leis mais atuais incluíam, de forma mais clara, discriminada e ampla, as categorias temáticas. Com este objetivo, procedeu-se à análise estatística de correlação linear utilizando o software SPSS. Foram analisadas as associaçóes entre o ano de criação da lei de SME (1997 a 2008) e a avaliação qualitativa de cada 
uma das dez categorias temáticas. Encontrou-se correlação estatisticamente significativa entre o ano de criaçáo da lei e apenas cinco entre as dez categorias temáticas: gestão democrática, valorização do professor, Plano Municipal da Educação, ação redistributiva e referências locais.

Para a variável "gestão democrática", há uma correlação positiva e estatisticamente significativa entre as duas variáveis $(r=, 349 ; p=, 000)$. Ou seja, quanto maior o ano de criação da lei, maior a avaliação da gestão democrática. Isso indica que leis criadas mais recentemente permitem uma melhor gestão democrática nos sistema de ensino. Da mesma forma para "ação redistributiva" $(r=, 304 ; p=, 000)$, assim como para "Plano Municipal de Educação" ( $r=, 283 ; p=, 000)$. Para a variável "referências locais", a correlação é estatisticamente significativa e negativa, indicando que leis criadas mais recentemente tendem a considerar menos aspectos voltados para condiçóes do contexto local $(r=-, 136 ; p=, 044)$.

Para a variável "valorização dos profissionais da educação", a correlação é estatisticamente significativa e positiva $(r=, 380 ; p=, 000)$. Este resultado indica que leis criadas mais recentemente (quanto maior o ano de criação da lei) apresentam uma melhor avaliação dos profissionais da educação.

O dado relevante para este artigo é que a categoria temática relacionada à valorização dos profissionais da educação vem sendo mais bem e mais significativamente tratada, mais consistentemente formulada nas leis de SME, embora nem todas as leis de SME a refiram.

Para a discussão detalhada de cada categoria, um nível mais aprofundado de análise do conteúdo foi desenvolvido, como se verá a seguir com relação à categoria temática "valorização dos profissionais da educação", foco deste texto. Serão utilizados trechos de algumas leis de SME como exemplos do conteúdo analisado sem, entretanto, referir a que município elas pertencem, para manter o anonimato da fonte.

\section{Valorização e formação do professor: referências nos Sistemas Municipais de Ensino}

Para o Conselho Nacional de Educação, sistema de ensino é o

[...] conjunto de campos de competências e atribuiçôes voltadas para o desenvolvimento da 
educação escolar que se materializam em instituiçóes, órgãos executivos e normativos, recursos e meios articulados pelo poder público competente abertos ao regime de colaboração e respeitadas as normas gerais vigentes. (BRASIL, 2000, seção 1, p. 25).

É uma concepção de sistema de ensino extensivo a qualquer instância que o institua e administre.

Para o caso dos sistemas municipais, entende-se que sistema é uma forma peculiar de as forças sociais locais interpretarem e inscreverem-se na educação brasileira, explicitando traços característicos e de identidade próprios, incluindo, e não exclusivamente centrando, a ação na criação de estruturas institucionais (órgãos normativos e executivos), focalizando a educação escolar, em especial a Educação Básica, independente de sua mantenedora (WERLE, THUM, ANDRADE, 2008). Tal possibilidade precisa explicitar-se em lei, e sua formulação pressupóe o exercício de prática de autonomia e responsabilização dos atores locais (executivo, legislativo municipal, Conselho Municipal de Educação, sindicato e associação de docentes, escolas públicas, escolas privadas, pais, alunos e cidadãos da localidade).

Um sistema de ensino opera por meio da ação profissional de seus professores. É com formação específica, estímulo e oportunidades de qualificação continuada, atenção à sua profissionalização e carreira, que os SMEs demonstram preocupação, alcançam e consolidam qualidade de ensino.

Sabe-se que a lei que cria o SME não é o documento estruturador inaugural no âmbito municipal. Os municípios, mesmo sem seu próprio sistema, podem ter implantado um plano de carreira para seus professores. A preocupação com a carreira do magistério recebeu, em 1997, recomendaçóes específicas, extensivas a todo o território nacional, por meio de resolução do Conselho Nacional de Educação que fixou diretrizes de elaboração para planos de carreira e remuneração do magistério dos Estados, Distrito Federal e municípios. Ademais, as municipalidades têm instituído, por meio de editais, concursos e normas de seleção, os critérios de titulação mínimos para o exercício do magistério. A lei de SME, entretanto, pressupóe uma articulação global de todos os princípios, normas e elementos fundamentais à estruturação e ao funcionamento da educação, sendo uma oportunidade de 
retomada, objetivando coesão e integração do quadro legal que estrutura a educação local. Neste quadro, o papel de todos os profissionais da educação é central, e não há como não referi-los.

A maioria (79\%), embora não a totalidade dos municípios que criaram SME no RS, referem a valorização do professor. Alguns deles o fazem de maneira ampla, indicando o tema como princípio que orientará o SME. Outros, demonstrando um nível maior de percepção do funcionamento do sistema e da importância dos profissionais da educação, estendem, para além do professor que atua em sala de aula, a concepção de educadores envolvidos na educação escolar e contemplam diversas dimensões da profissão docente.

$\mathrm{Na}$ organização dos dados desta pesquisa, se identificam níveis de formulação do tema no texto das leis de SME: preliminar, transcritivo, elaborado.

Situa-se como nível Preliminar aquele que apenas cita o princípio da valorização do profissional da educação escolar. São casos em que não há desdobramento nem pela referência à formação, à titulação mínima, nem às condições de trabalho, nem à carreira do magistério, nem às condiçóes para educação continuada destes profissionais. Chama-se de preliminar, pois um princípio que não se faz acompanhar de sua operacionalização, que não se desdobra em níveis mais concretos de explicitação, indica que não foi inspirador para a estruturação da educação municipal. Ora, o princípio "valorização do magistério" que não é desdobrado na lei dos SME, demonstrando formas, modalidades, estruturas que materializem esta valorização, permanece letra morta. São indiscutíveis a centralidade do professor e a relação do empenho e da qualidade de sua ação para o funcionamento do sistema de ensino. Diante da ausência de diretrizes voltadas para a valorização do magistério, a política pública municipal entra em colapso, demonstrando apenas sua face burocratizadora, e não sua dimensão de autonomia local e de processos de mudança social.

Identifica-se como nível Transcritivo aquele cuja formulação está muito colada no texto da LDBEN e em documentos legais federais anteriores à própria lei do SME. O conteúdo identificado neste nível cita: a valorização dos profissionais da educação, o estatuto e o plano de carreira do magistério público, o ingresso exclusivamente por concurso público de provas e títulos, o aperfeiçoamento profissional continuado, a progressão funcional baseada na titulação ou habilitação e na avaliação de desempenho, 
um período reservado para estudos, planejamento e avaliação, incluído na carga horária de trabalho, bem como condiçóes adequadas de trabalho. Sáo formulaçóes, entretanto, que seguem muito de perto a da LDBEN sem acenar para a criação de espaços institucionais peculiares às condiçóes municipais. Na medida em que a valorização do professor é limitada à letra da LDBEN, sua tematização na lei de SME não é promissora na direção de autonomia política dos governos locais. Ao contrário, demonstra submissão e uma ambiência em direção à ingerência e à permeabilidade, mais do que autonomia, criatividade e atenção às peculiaridades locais.

Num terceiro nível, situam-se leis que desdobram o tema da formação de valorização do professor de diferentes maneiras. Nesta categoria, há leis que identificam:

- a importância do professor;

- funçóes de apoio pedagógico;

- destaque à função de diretor de escola;

- funcionários da merenda, limpeza e outros servidores da escola.

\section{Importância do professor}

Em algumas leis de SME, há formulações que denotam a importância e o espaço de atuação do professor. Em geral, indicam valorização por mencionarem o protagonismo do professor no planejamento, desenvolvimento e avaliação de açóes pedagógicas e de gestão da educação. Entre estas evidências, estão: participar da elaboração da proposta pedagógica da escola e do regimento escolar, responsabilizar-se por um adequado plano de trabalho escolar, zelar pela aprendizagem dos alunos, estabelecer estratégia de recuperação de alunos. Em alguns aspectos, as leis de SME repetem o texto da LDBEN, mas de qualquer forma indicam certo nível de atenção para com o professor.

Pode-se levantar a hipótese de que muito há a ser explicitado pelo SME quanto à importância do professor, de forma a considerar seu alto valor social. A formação docente exige cursos de longa duração, a natureza de seu trabalho e de sua formação aponta para a relevância de oferecer ao professor salários compatíveis, carga horária que lhe permita fixar-se em uma única escola, na qual ele tenha tempo suficiente para, efetivamente, participar 
da gestão da escola, da elaboração de seu projeto político-pedagógico, das reunióes de colegiado, do atendimento às demandas da comunidade, além de orientar os alunos em seus estudos e realizar atividades de reforço.

Por certo, estes itens poderiam ser somente identificados nas leis de SME, e seu desdobramento seria explicitado em regulamentação posterior. Sugerem, também, a necessidade de regulamentação posterior às declaraçóes amplas, tais como oportunizar aos professores formas de desenvolvimento profissional e modalidades de progressão funcional articulando titulação e avaliação do desempenho. Neste aspecto, os Conselhos Municipais de Educação têm papel relevante, qual seja, o de verificar suas atribuiçóes e acompanhar as demandas de valorização dos profissionais da educação apenas enunciadas na lei de SME (WERLE, 2008).

\section{Funçóes de apoio pedagógico}

Há leis que identificam, ao lado de professores, outros profissionais que dão apoio pedagógico ${ }^{6}$, técnico-administrativo e serviços de apoio ou desempenham atividades especiais dentro do sistema de ensino, especificando suas funções e exigências prévias ao exercício de suas tarefas. Pelo que se verifica, a expressão "suporte pedagógico" é empregada em sentido amplo, incluindo variada gama de profissionais da educação escolar.

Integram o quadro de profissionais da educação do Sistema Municipal de Ensino todos os membros do magistério que exercem atividades docentes ou dão suporte pedagógico ao Sistema, como supervisores e orientadores educacionais, e os que atuam nas áreas de administração e planejamento do complexo educacional, bem como os servidores da Rede Municipal de Ensino.

São membros do Magistério Público Municipal o conjunto de Professores e profissionais que oferecem suporte pedagógico direto às atividades dos docentes, como direção, supervisão, orientação e planejamento, nas unidades escolares e nos demais órgáos que compóe o Sistema Municipal de Educação, que desempenham atividades docentes ou especiais com vistas a alcançar os objetivos da educação. 
Em algumas leis de SME, há explicitação de condições para o desempenho de funçôes de suporte pedagógico, em geral, vinculadas à experiência docente. Tais leis afirmam que a experiência de docência é prérequisito para o exercício profissional de funções específicas de magistério, ou que o Município exigirá experiência docente de dois anos para o exercício profissional em "outras funções" vinculadas ao magistério.

Entre as leis que especificam outros profissionais além do professor, há as que referem o pedagogo, o supervisor, o diretor e o orientador educacional. A figura do Pedagogo é contemplada com especificações quanto à formação e às funçóes relacionadas ao cargo.

O pedagogo habilitado em curso superior de graduação em pedagogia com pós-graduação específica será responsável pelas: I - atividades de suporte pedagógico direto a docência na educação básica voltadas para o planejamento, administraçáo, supervisão, orientação e inspeção escolar.

A especificação do orientador educacional como membro da equipe do SME, quando ocorre, pode apresentar suas competências, como segue:

Compete ao Orientador Educacional:

- participar do processo de planejamento das atividades educacionais da Escola;

- trabalhar as relaçóes que se apresentam no processo ensinoaprendizagem;

- atuar junto aos educandos, sempre que necessário, estimulando situaçóes próprias para o trabalho cooperativo;

- cooperar para o processo de adaptação pessoal e social do aluno;

- desenvolver técnicas e hábitos de estudos que permitam ao aluno êxito no trabalho escolar;

- orientar para o trabalho, vocação e escolha profissional;

- promover a integração da escola com a família e a comunidade;

- socializar, de maneira ética, as informaçóes sobre o aluno com vistas a um fazer pedagógico que atenda a individualidade;

- promover a integraçáo de todos os serviços escolares, visando o sucesso do ensino-aprendizagem e o desenvolvimento pessoal do aluno; 
- desenvolver o auto-conceito e a auto-estima do professor de forma que sua atuação pedagógica seja prazerosa.

A referência ao supervisor explicita as competências que indicam sua ação no interior das escolas e no sistema de ensino, conforme se lê abaixo.

Compete ao Supervisor Escolar:

- atuar na ação técnico Pedagógica, visando a promoção e manutenção da unidade de atuação docente;

- promover a melhoria no Sistema Municipal de Ensino no que tange à aprendizagem e à globalização dos diferentes componentes curriculares;

- socializar o saber docente, fomentando a troca de experiências entre os elementos das escolas; d) Assessorar as Escolas na correção dos desvios;

- coordenar o processo de elaboração da proposta Pedagógica.

Esta especificação acentua o trabalho de coordenação e de articulação do supervisor junto ao corpo docente e às escolas da rede, em perspectiva que diverge da que vem sendo instituída em documentos de política de âmbito federal, como por exemplo, o Plano de Metas Compromisso Todos Pela Educação do governo federal, que acentua outra dimensão do trabalho do supervisor muito mais voltada para assegurar a performatividade do trabalho docente (ver cultura de performatividade competitiva em BALL, 2005). Tal plano especifica a ideia de que, junto ao núcleo gestor da escola, devem ser incorporados coordenadores pedagógicos, mas com o objetivo de acompanhar as dificuldades do professor.

Portanto, estes outros profissionais que fornecem o apoio pedagógico em escolas e nas secretarias de educação dos municípios são caracterizados, nas leis que criam SME, por uma ação mais compreensiva e voltada para o coletivo da escola, e pela área de atuação e experiência docente prévia. Há, entretanto, algumas que os caracterizam pela formação/habilitação prévia. São casos que seguem a LDBEN ao indicar que a formação de profissionais de educação para administração, planejamento, inspeção, supervisão e orientação educacional para a Educação Básica será feita em cursos de graduação em Pedagogia ou em nível de pós-graduação. 
Os Especialistas em Educação, habilitados em: Administração, Supervisão e Inspeção Escolar e Orientação Educacional são responsáveis por suas especificidades nos Estabelecimentos de Educação Infantil, Ensino Fundamental e nos Órgãos do Sistema Municipal de Ensino. A carreira dos especialistas em Educação e de Direção dos estabelecimentos de Ensino será regulamentada em instrumento próprio dentro da Gestão Democrática da Escola Municipal.

Ora, vários questionamentos podem ser propostos quanto às exigências de que o apoio pedagógico seja prestado apenas por titulados com habilitação específica. Um deles decorre do fato de que os profissionais da educação circulam, ao longo de sua vida profissional, entre várias funçóes. Por outro lado, as designaçóes de funçôes na área da educação são fluidas (WERLE, 2001). Entretanto, ao longo de seu percurso profissional os supervisores e gestores desempenham diferentes funçóes a partir das necessidades e possibilidades da escola e do sistema de ensino, bem como das necessidades que se originam em sua vida particular. Ao longo de seu percurso, se constroem como pessoas e como profissionais em vários espaços e funçóes: passam pela sala de aula, pela secretaria, pela biblioteca. Ora são supervisores de escola, ora atuam na Secretaria Municipal de Educaçáo, ora na Coordenadoria Regional de Educação (CRE) ou em departamentos na Secretaria Estadual de Educação, ou ainda realizam o trabalho de supervisão circulando, dividindo seu tempo entre diferentes escolas. A vice-direção, a direção e a coordenação pedagógica (supervisão) são espaços em que tanto gestores como supervisores circulam. A alternância ocorre não apenas entre funçóes, mas, também, entre instituições de diferentes mantenedoras (escolas particulares e estabelecimentos públicos), entre diferentes redes (estabelecimento público municipal e publico estadual) e inclusive entre diferentes municípios. A alternância expressa não apenas o desempenho de funçóes em sequência, mas de forma concomitante (supervisor e escola privada, e professor em escola pública, por exemplo).

A alternância de funçóes que concretamente se observa entre os educadores indica que a lei de SME não pode estabelecer uma articulação rígida entre habilitação e ação profissional. A constatação de alternância 
entre funçóes de apoio, docente e outras sugere que as leis de SME devem ser explicitas quanto à formação e valorização do magistério, mas não rígidas, a ponto de engessarem o funcionamento do sistema.

Outro questionamento é mais especificamente relacionado à exigência de formação superior para o exercício de açóes de apoio. Embora seja desejável a busca de profissionais com formação obtida em nível cada vez mais avançado, não há como colocá-la como pré-requisito e condição primeira para selecionar educadores para promover o apoio pedagógico, pela inexistência de oferta destes profissionais em todos os cantos do Estado do Rio Grande do Sul. Há, portanto, formulações mais flexíveis, baseadas na formação docente como pré-requisito, associada à experiência em escola, mas outras que, por serem muito exigentes em certos temas relacionados ao professor, podem levar à impossibilidade de atendê-las, fomentando a precarização do trabalho mediante contratos temporários, a desprofissionalização da educação, até a ausência total destes profissionais no sistema escolar.

\section{Destaque à função de diretor de escola}

Como assinalado anteriormente, há leis que referem os demais profissionais que oferecem apoio pedagógico ao trabalho docente, mantendo o nível geral de designação - pedagogo, especialistas da educação. Há, entretanto, municipalidades que individualizam o diretor de escola ${ }^{7}$ no contexto do SME e especificam suas atribuiçôes. São SME que identificam o diretor de escola como um articulador interno ao estabelecimento de ensino, bem como com responsabilidades diante da secretaria municipal de educação e diante do Conselho Municipal de Educação e demais colegiados de gestão de questôes socioeducacionais da localidade. Este nível de esclarecimento é positivo e demonstra como tais municípios ocupam o espaço de autonomia que lhes cabe na política educacional.

Entre as leis que especificam a função e as responsabilidades dos especialistas, algumas referem a direção de escola da forma transcrita a seguir.

Cabe ao Diretor da escola:

- coordenar as atividades da escola, previstas no plano integrado;

- coordenar os recursos humanos e financeiros visando o desenvolvimento da política educacional do Sistema Municipal de Ensino; 
- participar do processo administrativo pedagógico da escola;

- representar a escola em eventos educacionais, cívicos e sociais, sempre que necessário.

Compete ao Administrador Escolar ou Diretor:

- dirigir o processo Administrativo e Pedagógico da Escola;

- coordenar recursos humanos e financeiros, visando o desenvolvimento da política educacional do Sistema Municipal de Ensino;

- coordenar a construção e a execução do Projeto Político Pedagógico da Escola;

- dar cumprimento às legislaçóes do Ensino;

- observar as normas legais do Conselho Municipal de Educação;

- observar as condiçóes de acesso e permanência dos alunos na Escola;

- observar os índices de aprovação e repetência;

- avaliar a execução dos currículos, dos programas de ensino;

- zelar pelo cumprimento das normas do Regimento Escolar;

- promover o atendimento às necessidades e à qualidade dos recursos físicos, do prédio, das instalaçóes e dos equipamentos;

- manter a regularidade dos registros da documentação do corpo discente, docente e técnico-administrativo;

- acompanhar a execução de programas sociais complementares;

- representar a Escola em eventos educacionais, cívicos e sociais, sempre que necessário.

\section{Importância dos servidores da merenda e limpeza escolar}

É preciso considerar, para a discussão do tema "funcionários de escola" na lei dos SME, uma legislação federal recente - Lei no 12.014, de 6 de agosto de 2009 -, que altera o artigo 61 da LDBEN (BRASIL, 2009). Recorde-se que o artigo 61 da LDBEN, o primeiro do título VI, "Dos profissionais da Educação", refere os fundamentos da formação dos profissionais da educação sem discriminar quem seriam estes profissionais. Com a atual formulação, ficam identificados os profissionais da Educação 
Escolar Básica, contanto que estejam em efetivo exercício e possuam formação em cursos reconhecidos. Portanto, a nova lei de agosto de 2009 discrimina as categorias de trabalhadores que devem ser considerados profissionais da educação, incluindo: professores habilitados em nível médio ou superior para a docência na Educação Infantil, no Ensino Fundamental e Médio; trabalhadores em educação portadores de diploma de Pedagogia ou com títulos de mestrado ou doutorado em área de Educação e trabalhadores em educação, portadores de diploma de curso técnico ou superior em área pedagógica ou afim. De fato, a Lei n. 12.014/09, por ser muito recente, não interfere na formulação que as leis de SME analisadas neste artigo apresentam quanto a funcionários de escola, entretanto é necessário considerá-la como um cenário próximo a intervir na organização da educação municipal.

Poucas leis de SME referem os funcionários de escola, os quais, inclusive, são designados de não membros do magistério, servidores da educação ou profissionais da educação, neste caso, antecedendo a terminologia adotada na Lei n. 12.014/09. Assim, por exemplo, uma lei de SME assim refere: "São funcionários da educação os profissionais não membros do magistério que exercem funçóes correlatas ou de suporte ao processo de ensino e aprendizagem em unidades escolares ou órgãos centrais e intermediários do SME” (BRASIL, 2009).

Há estudos (WERLE, 2005b) que indicam a importância da contribuição destes profissionais para o projeto de escola, para a indicação de peculiaridades de comportamento do corpo discente, pois serventes e merendeiras convivem com professores, alunos, pais, em momentos informais, observando-os e produzindo leituras diversas das que usualmente circulam nas escolas a partir do olhar dos professores e da direção. Serventes e merendeiras são, também, portadoras de saberes que precisam ser valorizados no processo político-pedagógico e nos colegiados escolares, de forma que a eles não seja apenas dado espaço como legitimadores de interesses e decisóes de outros segmentos da comunidade escolar (WERLE, 2003) nem que seu trabalho passe invisível no dia-a-dia da escola, notado apenas quando deixa de ser realizado.

\section{Elementos conclusivos}

Este texto discutiu alguns aspectos do conteúdo das leis que criam sistemas municipais de ensino em municípios do Rio Grande do Sul com 
o argumento de que a iniciativa de criar seu próprio sistema de ensino evidencia o caminho de autonomia e responsabilização dos governos locais. É um trabalho que demonstra, a partir da instância municipal, como a descentralização é assumida, estruturada e configurada no tema específico da formação e valorização do magistério. Ressalvando que o texto legal é apenas uma fase dos processos de articulação das políticas educacionais e que sua letra contempla apenas uma pequena face da dinâmica e da complexidade que são as políticas educacionais de instauração de sistemas municipais de ensino, conclui-se que, mesmo sem aprofundar a temática da formação e valorização do magistério, a criação de SME é em si um passo importante e promissor de autonomia dos governos locais. Por outro lado, vale lembrar que a criação de SME é um momento que precisa ser acompanhado de perto por meio de regulamentação de temas, articulações das forças locais como o Conselho Municipal de Educação, Associaçãao de Professores, Associação de Pais, professores, diretores e cidadãos interessados em qualificar a educação.

A valorização e a formação do magistério são temas relevantes para a estruturação de um sistema de ensino e conteúdo necessário das leis de SME. Tal importância, entretanto, não se evidencia em todas as leis de SME estudadas. Algumas leis não citam o tema dos profissionais da educação, outras o fazem de maneira muito ampla e imprecisa. Outras ainda referem tal tema, repetindo o que já foi explicitado pela LDBEN. Por fim, algumas detalham elementos referentes ao pessoal de apoio pedagógico, reconhecem especificidades do diretor de escola e indicam reconhecer a importância do professor. As leis de SME, entretanto, são, em sua maior parte, silenciosas quanto ao pessoal de apoio escolar como serventes e merendeiras.

Tomando os municípios como atores importantes no processo de descentralização da educação e qualificação do ensino, pode-se afirmar que a criação de SME é uma estratégia importante de regulação da educação. O governo local, por um lado, se apropria e transforma regras produzidas em outras instâncias, mormente as de âmbito federal, embora esta apropriação não se faça sem considerar as regras e normas produzidas em outras instâncias do sistema político-administrativo da educação e sem demonstrar apropriação diversificada conforme as condiçóes locais. 


\section{Notas}

1 Trabalho produzido no contexto do projeto "Gestão democrática e qualidade da Educação Básica”, apoiado pelo Edital Observatório de Educação INEP/Capes.

2 Autonomia política é vinculada a governos locais, conforme termo conceituado por Souza e Blumm (apud DUARTE, 2001, p. 2).

3 O estudo Estatísticas do século XX, publicado pelo IBGE - Instituto Brasileiro de Geografia e Estatística, indica que a população brasileira triplica na primeira metade do século XX e mais que triplica novamente na segunda metade (SILVA, BARBOSA, 2003, p. 31). Entretanto, no final do século XX o País apresenta tendência à desconcentração e à desmetropolização, pois a partir dos anos 1980 o ritmo de urbanização se reduz. Há grande diferenciação nas taxas de urbanização no País, sendo de $91 \%$ na Região Sudeste, 70\% nas Regióes Norte e Nordeste, de 81\% na Região Sul e de $87 \%$ na Região Centro-Oeste (SILVA, BARBOSA, 2003, p. 49).

4 O federalismo de integração é um termo cunhado por Sallum Jr., autor citado por Duarte (2001). O federalismo de integração surgiu no período pós-64 indicando que agências federais, representadas localmente por meio de escritórios regionais, passaram a atuar oferecendo assistência técnica e financeira, diretamente, a Estados e municípios, em áreas que eram de atuação original destas instâncias.

5 Na coleta de dados, houve uma articulação com a Federação das Associações de Municípios do Rio Grande do Sul (Famurs), com o Conselho Estadual de Educação do Rio Grande do Sul e com alguns municípios diretamente.

6 Nos itens que seguem, serão citados trechos de leis de Sistemas Municipais de Ensino de vários municípios do Rio Grande do Sul. Não serão identificados os municípios nem os documentos legais a que pertencem, pois não se objetiva identificar este ou aquele município como o que apresenta a melhor ou mais completa formulação, mas trabalhar conceitualmente o tema em estudo.

7 Para uma análise mais detalhada do tema direção de escolas em leis de SME, ver (WERLE, MANTAY, ANDRADE, 2009). 


\section{Referências}

ASSUMPÇÃO, Eracilda de. Planos municipais de educação: as interfaces da caminhada de construçáo. 2006. Dissertação (Mestrado em Educação) - Programa de Pós-Graduação em Educação, Universidade do Vale do Rio dos Sinos, São Leopoldo.

BALL, Stephen J. Cidadania global, consumo e política educacional. In: SILVA, Luiz Heron da (Org.). A escola cidadã no contexto da globalização. Petrópolis: Vozes, 1998. p. 121- 137.

BALL, Stephen J. Diretrizes políticas globais e relações políticas locais em educação. Currículo sem Fronteiras, Porto Alegre, v. 1, n. 2, p. 99-116, jul./dez. 2001.

BALL, Stephen. Profissionalismo, gerencialismo e performatividade. Cadernos de Pesquisa, São Paulo, v.35, n.126, set./dez. 2005, p. 521-539.

BARRETO, Maria Inês. Inserçáo internacional de governos locais. Teoria \& Debate, São Paulo, v.17, n.59, p. 12-16, ago./set. 2004.

BARRETO, Maria Inês; VIGEVANI, Tullo. Cenário global e o espaço de intervençáo dos governos locais. In: MARTINS, Ângela Maria; OLIVEIRA, Cleiton de; BUENO, Maria Sylvia Simóes. Descentralização do Estado e municipalização do ensino: problemas e perspectivas. Rio de Janeiro: DP\&A, 2004. p. 29-56.

BRASIL. Ministério da Educaçáo. Lei no 9.394, de 20 de dezembro de 1996. Estabelece as diretrizes e bases da educaçáo nacional. Portal do Ministério da Educação: legislação. Brasília, DF,1996. Disponível em: $<$ http://portal.mec.gov.br/setec/arquivos/pdf1/proejalei9394.pdf_>. Acesso em: 2 fev. 2008.

BRASIL. Conselho Nacional de Educação. Parecer CNE/CEB 30/2000. [Undime]. Solicita pronunciamento tendo em vista o Parecer CEB 04/2000. Aprovado em 12/9/2000. DOU, Brasília, DF, de 6 out. 2000. seção 1, p. 25. Disponível em: <http://portal.mec.gov.br/cne/arquivos/ pdf/pceb030_00.pdf>. Acesso em: 10 fev. 2009.

BRASIL. Senado Federal, Secretaria Especial de Editoraçáo e Publicaçóes, Subsecretaria de Ediçôes Técnicas [Constituição (1988)]. Constituição 
da Republica Federativa do Brasil: promulgada em 5 de outubro de 1988. Texto consolidado até a Emenda Constitucional n. 58 de 23 de setembro de 2009. Brasília: Senado Federal, 2009. 58 p. Disponível em: <http:// www.senado.gov.br/sf/senado/seep/asp/apresentacao.asp. CN_Federal_ CF_1988.pdf>. Acesso em: 14 set. 2009.

BRASIL. Leis, decretos, pareceres. Lei n. 12.014, de 6 de agosto de 2009. Altera o art. 61 da Lei n. 9.394, de 20 de dezembro de 1996, com a finalidade de discriminar as categorias de trabalhadores que se devem considerar profissionais da educação. DOU, Brasília, DF, de 7 ago. 2009. Disponível em: <HTTP://legislacao.planalto.gov.br/legisla/legislacao. nsf/Viw_Identificacao/lei12.014_2009?Document>. Acesso em: 30 ago. 2009.

BRASIL. Leis, decretos, pareceres. Lei n. 10.172/2001, de 9 de janeiro de 2001. Aprova o Plano Nacional de Educação e dá outras providências. Disponível em: <http://www.diariooficial.hpg.com.br/plano_nac_ educacao.htm>. Acesso em: 1ำago. 2009.

BRASIL, Leis decretos, pareceres. Presidência da República. Casa Civil. Subchefia para Assuntos Jurídicos. Decreto n. 6.094, de 24 de abril de 2007. Dispóe sobre a implementação do Plano de Metas Compromisso Todos pela Educação, pela União Federal, em regime de colaboração com Municípios, Distrito Federal e Estados, e a participação das famílias e da comunidade, mediante programas e ações de assistência técnica e financeira, visando à mobilização social pela melhoria da qualidade da educação básica. Disponível em: <http://www.planalto.gov.br/ccivil_03/_ Ato2007-2010/2007/Decreto/D6094.htm>. Acesso em: 14 jul. 2009.

CORTESÃO, Luiza; MAGALHÁES, António; STOER, Stephen. Mapeando decisóes no campo da educação no âmbito do processo da realização das políticas educativas. Educação, Sociedade \& Culturas, Porto/ PT, n.15, p. 45-58, 2001.

CUNHA, Luis Antonio. A reorganização do campo educacional: as conferências de educação. Educação \& Sociedade, Campinas, SP, v. 3, n. 9, p. 3-48, maio 1981.

DIAS-DA-SILVA, Maria Helena Galvão Frem. A fragilização da escola pública, a glorificação dos saberes docentes e a minimização do 
conhecimento educacional. In: TRAVERSINI, Clarice et al. (Org.) Trajetórias e processos de ensinar e aprender: práticas e didáticas. Porto Alegre: Edipucrs, 2008. p. 425-444.

DOURADO, Luis Fernandes. Políticas e gestão da educação básica no Brasil: limites e perspectivas. Educação e Sociedade, Campinas, SP, v. 20, n.100, p. 921-946, 2007.

DUARTE, Marisa Ribeiro Teixeira. Relaçóes intergovernamentais e regime de colaboração: o atendimento público na educação escolar básica. In: REUNIÃO ANUAL DA ANPED, 24., 2001, Caxambu. Anais eletrônicos... Caxambu: ANPED, 2001. GT Estado e Política. Disponível em: <http://www.anped.org.br/24/tp.htm\#gt5>. Acesso em: 15 jan. 2009.

ESTRELA, Maria Teresa. A formação contínua entre a teoria e a prática. In: FERREIRA, Naura Syria Carapeto (Org.). Formação continuada e gestão da educação. 3. ed. São Paulo: Cortez, 2007. p. 43-64.

FERREIRA, Naura Syria Carapeto. Formação continuada e gestão da educação no contexto da "cultura globalizada". In: FERREIRA, Naura Syria Carapeto (Org.) Formação continuada e gestão da educação. 3. ed. Sáo Paulo: Cortez, 2007. p. 17-42.

FREY, Klaus. Políticas públicas: um debate conceitual e reflexóes referentes à prática da análise de políticas públicas no Brasil. Planejamento e Politicas Públicas, Brasília, n. 21, p. 211-259, jun. 2000.

GHENO, Eliane Teresinha. Politicas educacionais e processo de divulgação: o caso do Plano Municipal de Educação de Esteio. 2008. Dissertação (Mestrado em Educação) - Programa de Pós-Graduação em Educação, Universidade do Vale do Rio dos Sinos, São Leopoldo.

GIDDENS, Anthony. As conseqüências da modernidade. São Paulo: Unesp, 1991.

. Modernidade e identidade. Rio de Janeiro: Zahar, 2002.

LOPES, Alice Casimiro. Políticas curriculares: continuidade ou mudança de rumos? Revista Brasileira de Educação, Rio de Janeiro, n. 26, p. 109118, maio/ago. 2004. 
SAVIANI, Dermeval. História da formação docente no Brasil: três momentos decisivos. Educação: Revista do Centro de Educação da UFSM, Santa Maria, n. 30, p. 11-26, 2005.

SILVA, Nelson do Valle Silva; BARBOSA, Maria Lígia de O. População e estatísticas vitais. In: INSTITUTO BRASILEIRO DE GEOGRAFIA E ESTATÍSTICA. Estatísticas do século XX. Rio de Janeiro: Centro de Documentação e Disseminação de Informações/IBGE, 2006.

STOER, Stephen; MAGALHÃES, António. A diferença somos nós: a gestão da mudança social e as políticas educativas e sociais. Porto: Afrontamento, 2005.

STROMQUIST, Nelly P. Políticas públicas de estado e eqüidade de gênero. Revista Brasileira de Educação, Rio de Janeiro, n. 1, p. 27-49, jan./ abr.1996.

TANURI, Leonor Maria. História da formação de professores. Revista Brasileira de Educação, Rio de Janeiro. n. esp.14, p. 61-88, maio/ ago.2000. 500 anos de educação escolar.

VEIGA, José Eli da. Cidades imaginárias: o Brasil é menos urbano do que se calcula. 2. ed. Campinas, SP: Autores Associados, 2003.

VIEIRA, Sofia Lerche. Educação básica: política e gestão da escola. Fortaleza: Liberlivros, 2008.

Escola - função social, gestão e política educacional. In: FERREIRA, Naura Sirya Carapeto; AGUIAR, Márcia Ângela (Org.). Gestão da educação: impasses, perspectivas e compromissos. São Paulo: Cortez, 2001. p. 139-146.

; AlBUQUERQUE, Maria Gláucia Menezes. Política e planejamento educacional. Fortaleza: Ediçóes Demócrito Rocha, 2001. WERLE, Flávia Obino Corrêa. Conselhos escolares: implicaçôes na gestão da escola básica. Rio de Janeiro: DP\&A, 2003.

- Novos tempos, novas designaçóes e demandas: diretor, administrador ou gestor escolar. Revista Brasileira de Politica e Administração da Educação - RBPAE, Porto Alegre, v. 17, p. 147-160, 2001. 
WERLE, Flávia Obino Corrêa. O nacional e o local: ingerência e permeabilidade na educação brasileira. Bragança Paulista, SP: EUSF, 2005a.

- Terceirização e democratização na instituição escolar: serviços de merenda e limpeza. Revista Brasileira de Política e Administração da Educação-RBPAE, Porto Alegre, v. 21, p.115-135, 2005 b.

- CME como política estruturadora do campo da Educação no município. In: SOUZA, Donaldo Bello de (Org.). Conselhos municipais e controle social da educação: descentralização, participação e cidadania. São Paulo: Xamá, 2008. p. 211-232.

WERLE, Flávia Obino Corrêa; MANTAY, Carla; ANDRADE, Alenis Cleusa de. Direção de escola básica em perspectiva municipal. Revista Educação PUCRS, Porto Alegre, v. 32, n. 2, p. 139-149, 2009.

WERLE, Flávia Obino Corrêa; THUM, Adriane Brill e ANDRADE, Alenis Cleusa de. O Sistema Municipal de Ensino e suas implicaçóes para a atuação do Conselho Municipal de Ensino. Revista Brasileira de Política e Administração da Educação - RBPAE, Porto Alegre, v. 24, n. 1, p. 79 110, jan./abr. 2008. 


\section{Municipal education systems in Rio Grande do Sul, Brazil: a close look at the teacher}

\section{Abstract}

This article discusses municipal educational policies focusing on the theme of education and emphasis on teaching. It analyzes municipal educational systems (MES) in Rio Grande do Sul (RS) and the importance of decentralization and articulation of municipal education in the form of educational systems. The work is organized in five parts. The first presents a theoretical debate about political autonomy of local governments based on Giddens (1991, 2002). The second analyses educational policies considering laws governing MES within Brazil's constitutional framework. The third presents the emphasis on teaching in Brazilian legislation. The fourth presents methodology, while the fifth analyzes municipal laws governing municipal educational systems in Rio Grande do Sul, presenting their characteristics concerning the importance of the teacher and school directors, teachers aides and other employees who work in municipal education. It reaffirms the importance of the political autonomy of local governments.

Key words: Education and States. Politics and Education. Educational Systems.

\section{Sistemas municipales de enseñanza en Río Grande del Sur (Brasil): una mirada atenta para el profesor}

\section{Resumen}

El presente artículo discute las políticas educacionales en el ámbito municipal teniendo como tema central la formación y la valorización del magisterio. Analiza las leyes del sistema Municipal de Enseñanza (SME) de Río Grande del Sur (RS) y la importancia de la descentralización, de la articulación de educación municipal en forma de sistema de enseñanza. El trabajo se estructura en cinco partes. La primera presenta un debate teórico sobre autonomía política de los gobiernos locales con base en Giddens (1991, 2002). La segunda analiza las políticas educacionales situando las leyes del Sistema Municipal de Enseñanza (SME) como parte del mundo constitucional. La tercera presenta la valorización del magisterio en la legislación brasilera. La cuarta presenta la metodología y la quinta parte analiza específicamente las leyes del SME del Municipio de Rio Grande del Sur explicitando sus características en relación al profesor y el director de escuela, y a los funcionarios que actúan en el SME, ya que se les ofrece apoyo pedagógico. Por último, se reafirma la importancia de la autonomía política de los gobiernos locales.

Palabras clave: Educación y Estado. Política y educación. Sistema de Enseñanza. 


\section{Flávia Obino Corrêa Werle}

Pós-Graduação em Educação

Universidade do Vale do Rio dos Sinos.

Av. Unisinos, 950,

CEP: 93022-000, São Leopoldo, RS.

Fone: (51) 3591-1100 Ramal: 1113, 1184.

E-mail: flaviaw@unisinos.com

\section{Carolina Obino Corrêa Werle}

E-mail: carolina.werle@grenoble-em.com

\section{Alenis Cleusa de Andrade}

E-mail: alenisb@yahoo.com.br 